«Системні технологіï» 1 (126) 2020 «System technologies»

DOI 10.34185/1562-9945-1-126-2020-17

УДК 622.647.82:51.001.57

Р.В. Кирия, С.В. Дзюба, Б.И. Мостовой

\title{
ОПТИМАЛЬНЫЙ ОБЪЕМ АККУМУЛИРУЮЩИХ БУНКЕРОВ, РАБОТАЮЩИХ В СИСТЕМЕ КОНВЕЙЕРНОГО ТРАНСПОРТА УГОЛЬНЫХ ШАХТ
}

Аннотация. Разработана математическая модель функционирования аккумулирующего бункера, работающего в системе конвейерного транспорта в режиме поддержания в нем объема груза в заданных пределах. При этом предполагалось, что интервалы времени простоев и работы надбункерной и подбункерной конвейерных линий распределяются по экспоненциальным законам. Определен максимальный объем аккумулирующего бункера, при котором пропускная способность системы «конвейер-бункер-конвейер» практически не увеличивается с увеличением объема бункера.

Ключевые слова: система конвейерного транспорта, аккумулирующий бункер, пропускная способность, экспоненциальный закон распределения, оптимальный объем бункера.

Введение. В системе подземного конвейерного транспорта угольных шахт широкое применение получили аккумулирующие бункеры. Они позволяют, за счет накопления груза в бункере, при остановке конвейерных линий некоторое время работать всей системе конвейерного транспорта и, тем самым, увеличить ее пропускную способность. Однако в настоящее время не существует методов определения оптимального объема аккумулирующего бункера, при котором пропускная способность системы конвейерного транспорта была бы наибольшей.

На подземном конвейерном транспорте угольных шахт с целью максимальной продолжительности работы лав аккумулирующий бункер работает в режиме поддержания объема груза в заданных пределах. При этом надбункерная конвейерная линия не останавливается и при достижения объемом груза в бункере максимального заданного значения $V_{2}$ питатель включается, а при достижении минимального заданного объема груза в бункере, равного $V_{1}$, питатель отключается (рис. 1) [1]. Этот

(c) Кирия Р.В., Дзюба С.В., Мостовой Б.И., 2020 
«Системні технології» 1 (126) 2020 «System technologies»

режим работы бункера возможен в случае, если средний грузопоток, поступающий в бункер $\bar{m}_{Q}$ меньшего среднего грузопотока, разгружаемого из бункера $\bar{Q}_{n}$, то есть, если $\bar{m}_{Q}<\bar{Q}_{n}$.

Если средний грузопоток, поступающий в бункер $\bar{m}_{Q}$ больше, либо равен среднему грузопотоку, разгружаемому из бункера $\bar{Q}_{n}$, то есть если $\bar{m}_{Q} \geq \bar{Q}_{n}$, то в режиме поддержания заданного объема груза в бункере подбункерная конвейерная линия не выключается и при достижении максимального заданного объема груза в бункере $V_{2}$ надбункерная конвейерная линия выключается, а при достижении минимального заданного объема груза $V_{1}$, надбункерная конвейерная линия включается.

В данной работе определена средняя пропускная способность простейшей системы «конвейер-бункер-конвейер» при работе аккумулирующего бункера в режиме поддержания заданного объема груза в бункере, то есть в управляемом режиме, в случае $\bar{m}_{Q}<\bar{Q}_{n}$ и в случае $\bar{m}_{Q} \geq \bar{Q}_{n}$. На основе полученных зависимостей найден максимальный объем аккумулирующего бункера, при котором средняя пропускная способность системы «конвейер-бункер-конвейер» наибольшая.

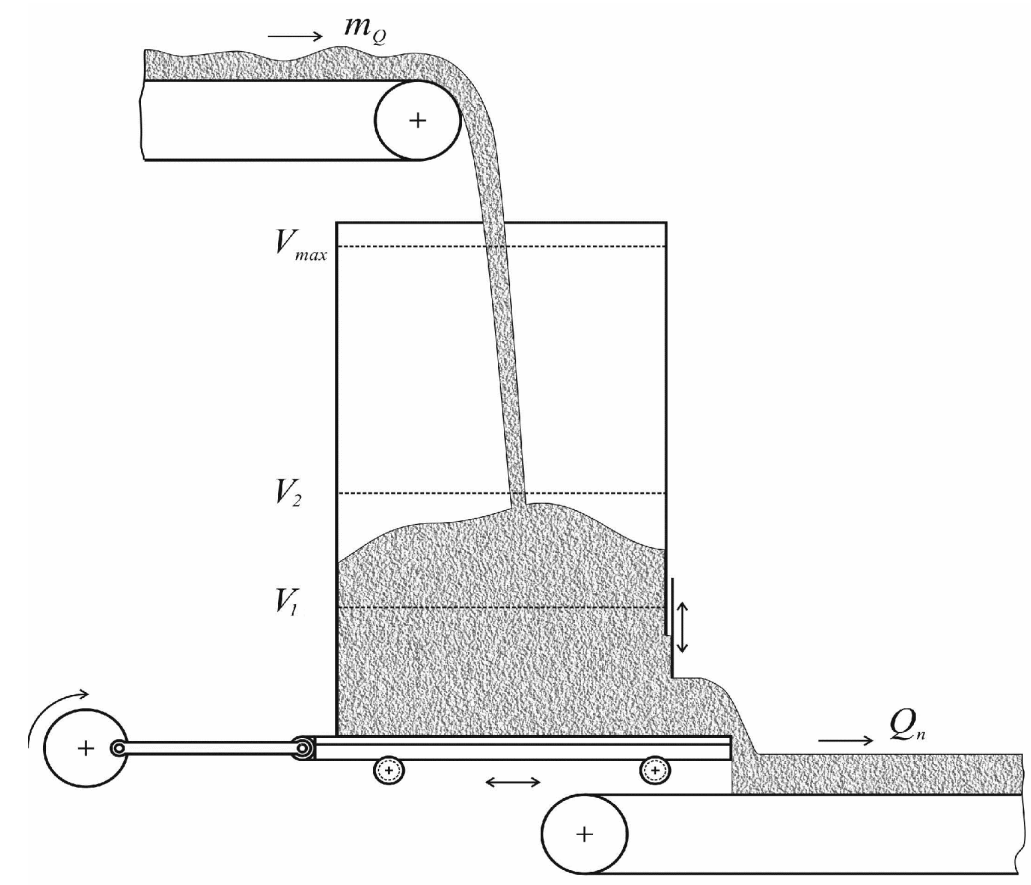

Рисунок 1 - Схема работы аккумулирующего бункера в режиме поддержания в нем объема груза в заданных пределах 
«Системні технологіï» 1 (126) 2020 «System technologies»

Предположим, что средняя величина грузопотока, поступающего на вход надбункерного конвейера, равна $m_{Q}$ (т/мин), коэффициенты интенсивностей простоев и восстановлений надбункерного и подбункерного конвейеров бункера равны $\lambda_{1}, \mu_{1}\left(\mathrm{Mин}^{-1}\right)$ и $\lambda_{2}, \mu_{2}\left(\right.$ мин $\left.^{-1}\right)$ соответственно; производительность питателя бункера равна $Q_{n}$ (т/мин); максимальный объем груза в бункере равен $V_{\max }\left(\mathrm{M}^{3}\right)$, а максимальный и минимальный заданные его объемы равны соответственно $V_{2}\left(\mathrm{M}^{3}\right)$ и $V_{1}\left(\mathrm{M}^{3}\right)$.

При этом средние грузопотоки (поступающий в бункер и разгружаемый из него) определяются по формулам [2, 3]:

$$
\bar{m}_{Q}=\frac{\mu_{1}}{\lambda_{1}+\mu_{1}} \cdot m_{Q} ; \bar{Q}_{n}=\frac{\mu_{2}}{\lambda_{2}+\mu_{2}} \cdot Q_{n} .
$$

Если аккумулирующий бункер работает в управляемом режиме и бункер не переполняется, т.е. объем груза в бункере не превышает максимально допустимого объема груза в бункере $V_{\max }$, и при этом надбункерная конвейерная линия не отключена, то средняя пропускная способность системы равна $\bar{m}_{Q_{1}}$.

Однако в случае достижения максимального заданного объема груза в бункере $V_{2}$ при неработающем подбункерном конвейере возможно переполнение бункера, т.е. достижение объема груза в бункере, равного объему бункера $V_{\max }$.

Обозначим через $P_{c}$ вероятность того, что бункер не переполнится. Тогда средняя пропускная способности системы «конвейер-бункерконвейер» будет равна

$$
m_{c}=P_{c} \cdot \bar{m}_{Q}
$$

Определим вероятность переполнения аккумулирующего бункера $\bar{P}_{c}$. Эта вероятность равна вероятности произведения двух независимых событий: вероятности простоя подбункерного конвейера $\bar{P}_{2}$ и вероятности того, что за время заполнения $T_{1}$ (мин) надбункерным конвейером бункера грузом объема $\Delta V_{2}=V_{\max }-V_{2}$ подбункерный конвейер не начнет работать.

Вероятность простоя подбункерного конвейера равна 
«Системні технології» 1 (126) 2020 «System technologies»

$$
\bar{P}_{2}=1-P_{2}=\frac{\lambda_{2}}{\lambda_{2}+\mu_{2}}
$$

где $P_{2}=\frac{\mu_{2}}{\lambda_{2}+\mu_{2}}-$ вероятность работы подбункерного конвейера в данный момент времени.

Вероятность того, что за время $T_{1}$ подбункерный конвейер не начнет работать, согласно экспоненциальному закону распределения времени его простоя, равна

$$
P_{2}^{\prime}=e^{-\mu_{2} T_{1}}
$$

Время $T_{1}$ заполнения бункера грузом до объема $\Delta V_{2}$ надбункерным конвейером при неработающем подбункерном конвейере определяется по формуле

$$
T_{1}=\frac{\rho \Delta V_{2}}{\bar{m}_{Q}} .
$$

Согласно теореме о вероятности произведений двух независимых событий вероятность переполнения бункера $\bar{P}_{c}$ равна

$$
\bar{P}_{c}=\bar{P}_{2} P_{2}^{\prime} \text {. }
$$

Подставляя (3) и (4) в (6), в результате получим вероятность переполнения бункера

$$
\bar{P}_{c}=\frac{\lambda_{2}}{\lambda_{2}+\mu_{2}} e^{-\mu_{2} T_{1}},
$$

где $T_{1}=\frac{\rho \Delta V_{2}}{\bar{m}_{Q}}$.

Вероятность непереполнения бункера $P_{c}$ определим по формуле

$$
P_{c}=1-\bar{P}_{c}=1-\frac{\lambda_{2}}{\lambda_{2}+\mu_{2}} e^{-\mu_{2} T_{1}}
$$

или с учетом (5) имеем:

$$
P_{c}=1-\frac{\lambda_{2}}{\lambda_{2}+\mu_{2}} e^{-\frac{\rho \Delta V_{2}}{\bar{m}_{Q}} \mu_{2}} .
$$

Подставляя (8) в (2), окончательно получим пропускную способность системы «конвейер-бункер-конвейер»в случае работы аккумулирующего бункера в управляемом режиме: 
«Системні технології» 1 (126) 2020 «System technologies»

$$
m_{c}=\left[1-\frac{\lambda_{2}}{\lambda_{2}+\mu_{2}} e^{-\frac{\rho \Delta V_{2}}{\bar{m}_{Q}} \mu_{2}}\right] \bar{m}_{Q},
$$

где $\Delta V_{2}=V_{\max }-V_{2}$.

Формула (7) совпадает с формулой работы [4], полученной для пустого бункера и постоянно работающего надбункерного конвейера.

В случае $\bar{m}_{Q}<\bar{Q}_{n}$ формулу (9) можно представить в виде:

$$
m_{c}=\left(1-\frac{\gamma_{2}}{1+\gamma_{2}} e^{-\frac{\rho \Delta V_{2}}{\bar{m}_{Q}} \mu_{2}}\right) \bar{m}_{Q},
$$

где $\bar{m}_{Q}=\frac{m_{Q}}{1+\gamma_{1}} ; \gamma_{1}=\frac{\lambda_{1}}{\mu_{1}} ; \gamma_{2}=\frac{\lambda_{2}}{\mu_{2}} ; \Delta V_{2}=V_{\max }-V_{2}$.

Проведя аналогичные выкладки, получим среднюю пропускную способность простейшей системы «конвейер-бункер-конвейер» в случае $\bar{m}_{Q} \geq \bar{Q}_{n}:$

$$
m_{c}=\left(1-\frac{\gamma_{1}}{1+\gamma_{1}} e^{-\frac{\rho \Delta V_{1}}{\bar{Q}_{n}} \mu_{1}}\right) \bar{Q}_{n},
$$

где $\bar{Q}_{n}=\frac{Q_{n}}{1+\gamma_{2}} \cdot ; \Delta V_{1}=V_{\max }-V_{1}$.

Анализ результатов. Из анализа формул (10) и (11) следует, что при больших значениях разностей $\Delta V_{2}$ и $\Delta V_{1}$, т.е. при $\Delta V_{2} \rightarrow \infty$ и $\Delta V_{1} \rightarrow \infty$, $m_{c} \rightarrow \bar{m}_{Q}$ и $m_{c} \rightarrow \bar{Q}_{n}$ соответственно.

Следовательно, пропускная способность системы «конвейербункер-конвейер», работающей в режиме поддержания объема груза в бункере в заданных пределах, в случае $\bar{m}_{Q}<\bar{Q}_{n}$ стремится к среднему грузопотоку $\bar{m}_{Q}$, поступающему в бункер, а в случае $\bar{m}_{Q} \geq{\overline{Q_{n}}}_{\text {стремится к }}$ среднему грузопотоку $\bar{Q}_{n}$, разгружаемому из бункера.

На рис. 2. показаны графики зависимости пропускной способности системы «конвейер-бункер-конвейер» при работе аккумулирующего бункера в управляемом режиме от $\Delta V_{2}$ в случае $\bar{m}_{Q}<\bar{Q}_{n}$ при различных значениях $\lambda_{2}==0,017 ; 0,025 ; 0,05$ мин $^{-1}$, рассчитанные по формуле (9). 
При этом исходные данные принимали значения: $\lambda_{1}=0,025$ мин $^{-1} ; \mu_{1}=$ 0,0614 мин ${ }^{-1} ; \mu_{2}=0,069$ мин $^{-1} ; m_{Q}=3,7$ т/мин; $\rho=1 \mathrm{~T} / \mathrm{M}^{3}$.

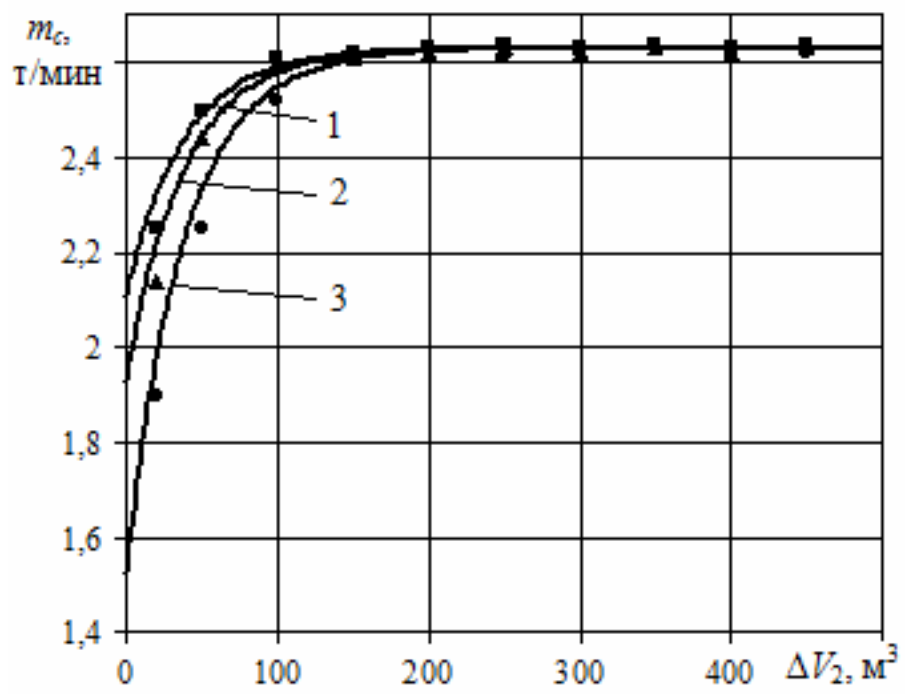

$$
1-\lambda_{2}=0,017 \text { мин }^{-1} ; 2-\lambda_{2}=0,025 \text { мин }^{-1} ; 3-\lambda_{2}=0,05 \mathrm{мин}^{-1}
$$

Рисунок 2 - Графики зависимости пропускной способности $m_{c}$ аккумулирующего бункера, работающего в управляемом режиме, от $\Delta V_{2}$ в случае $\bar{m}_{Q}<\bar{Q}_{n}$

Из графиков (см. рис. 2.) видно, что с увеличением $\Delta V_{2}$, т.е. с увеличением объема незаполненной грузом части аккумулирующего бункера, средняя пропускная способность $m_{c}$ системы «конвейер-бункерконвейер» увеличивается и при значениях $\Delta V_{2}>100 \mathrm{~m}^{3}$ независимо от значений $\lambda_{2}$ принимает постоянное значение, равное $\bar{m}_{Q}\left(\bar{m}_{Q}=2,63\right.$ Т/Мин).

Кроме того, из рис. 2. видно, что при значениях $0<\Delta V_{2}<100 \mathrm{M}^{3} \mathrm{c}$ увеличением $\lambda_{2}$ пропускная способность $m_{c}$ увеличивается.

На том же рисунке квадратиками, треугольниками и кружочками показаны результаты имитационного моделирования. Расхождение результатов теории и имитационного моделирования не превышает 3 \%.

Задаваясь малым значением разности є среднего значения пропускной способности бункера $m_{c}$ и среднего значения поступающего в бункер грузопотока $\bar{m}_{Q_{1}}\left(\bar{m}_{Q_{1}}-m_{c}=\varepsilon\right)$, из равенства (9) определяем макси- 
«Системні технології» 1 (126) 2020 «System technologies»

мальное значение объема аккумулирующего бункера независимо от режима его работы по формуле

$$
V_{\max }=\frac{m_{Q}}{\rho} \cdot \frac{\mu_{1} \ln \left(\frac{\lambda_{2}}{\lambda_{2}+\mu_{2}} \cdot \frac{\bar{m}_{Q_{1}}}{\varepsilon}\right)}{\mu_{2}\left(\lambda_{1}+\mu_{1}\right)}+V_{2}
$$

или

$$
V_{\max }=\frac{\bar{m}_{Q_{1}}}{\rho} \cdot \frac{\ln \left(\frac{\lambda_{2}}{\lambda_{2}+\mu_{2}} \cdot \frac{\bar{m}_{Q_{1}}}{\varepsilon}\right)}{\mu_{2}}+V_{2},
$$

где $\varepsilon-$ заданная точность $(\varepsilon=0,01)$, т/мин.

В случае $\bar{m}_{Q} \geq \bar{Q}_{n}$ надбункерная конвейерная линия останавливается, когда объем груза в бункере достигает значения $V_{2}$ и выключается, когда объем груза в бункере уменьшается до значения $V_{1}$. При этом питатель не отключается, т.е. работает постоянно.

В этом случае, проведя те же самые выкладки, согласно формуле (11) максимальный объем аккумулирующего бункера определяется по формуле

$$
V_{\max }=\frac{Q_{n}}{\rho} \cdot \frac{\mu_{2} \ln \left(\frac{\lambda_{1}}{\lambda_{1}+\mu_{1}} \cdot \frac{\bar{Q}_{n}}{\varepsilon}\right)}{\mu_{1}\left(\lambda_{2}+\mu_{2}\right)}+V_{1}
$$

или

$$
V_{\max }=\frac{\bar{Q}_{n}}{\rho} \cdot \frac{\ln \left(\frac{\lambda_{1}}{\lambda_{1}+\mu_{1}} \cdot \frac{\overline{Q_{n}}}{\varepsilon}\right)}{\mu_{1}}+V_{1} .
$$

Из формулы (12) следует, что максимальный объем груза в бункере, работающем в режиме поддержания в нем заданного объема груза, в случае $\bar{m}_{Q}<\bar{Q}_{n}$ определяется средним грузопотоком $\bar{m}_{Q}$, поступающим в бункер, зависит от интенсивностей потоков простоев и восстановлений $\lambda_{2}, \mu_{2}$ подбункерного конвейера и не зависит от производительности питателя $Q_{n}$.

Из формулы (13) следует, что максимальный объем груза в бункере, работающем в режиме поддержания в нем заданного объема груза, в 
«Системні технології» 1 (126) 2020 «System technologies»

случае $\bar{m}_{Q} \geq \bar{Q}_{n}$ определяется средним грузопотоком $\bar{Q}_{n}$, разгружаемым из бункера, зависит от интенсивностей потоков простоев и восстановлений $\lambda_{1}, \mu_{1}$ надбункерного конвейера и не зависит от грузопотока $m_{Q}$, поступающего в бункер.

Выводы. Разработана математическая модель функционирования аккумулирующего бункера, работающего в системе конвейерного транспорта в режиме поддержания в нем объема груза в заданных пределах.

Определен оптимальный объем аккумулирующего бункера, при котором с увеличением объема бункера пропускная способность системы «конвейер-бункер-конвейер» практически не увеличивается.

В результате установлено, что максимальный объем груза в бункере, работающем в режиме поддержания в нем заданного объема груза, в случае $\bar{m}_{Q}<\bar{Q}_{n}$ зависит от среднего грузопотока, поступающего в бункер, и не зависит от производительности питателя.

Кроме того, максимальный объем груза в бункере, работающем в режиме поддержания в нем заданного объема груза, в случае $\bar{m}_{Q} \geq \bar{Q}_{n}$ зависит от среднего грузопотока, разгружаемого из бункера, и не зависит от грузопотока, поступающего в бункер.

\section{ЛИТЕРАТУРА / ЛІТЕРАТУРА}

1. Кирия Р. В. Управление бункерами, работающими в системах конвейерного транспорта угольных шахт / Р. В. Кирия, В. Ю. Максютенко, Д.Д. Брагинец // Збірник наукових праць НГУ. - № 37. Дніпропетровськ, 2012. - С. 230-236.

2. Дружинин Г. В. Надежность автоматизированных производственных систем / Г. В. Дружинин. - М.: Энергоатомиздат, 1986. - 420 с.

3. Гнеденко Б.В. Математические методы в теории надежности / Б. В. Гнеденко, Ю. К. Беляев, А. Д. Соловьев. - М.: Наука, 1965. - 524 с.

4. Хенли Э.Дж. Надежность технических систем и оценка риска / Э. Дж. Хенли, Х. Кумамото. - М.: Машиностроение, 1984. - 528 с.

\section{REFERENCES}

1. Kiriia R. V. Upravlenie bunkerami, rabotayushchimi v sistemach konveyernogo transporta ugolnych shacht / R. V. Kiriia, V. Yu. Maksyutenko, D. D. Braginets // Zbirnyk naukovych prats NGU. - № 37. - Dnipropetrovsk, 2012. - P. 230-236. 
2. Druzhinin G. V. Nadezhnost avtomatizirovannych proizvodstvennych system / G. V. Druzhinin. - M.: Energoatomizdat, 1986. - 420 p.

3. Gnedenko B. V. Matematicheskie metody v teorii nadezhnosti / B. V. Gnedenko, Yu. K. Belyaev, A. D. Solovev. - M.: Nauka, 1965. - 524 p.

4. Khenly E. Dzh. Nadezhnost tekhnicheskikh system i otsenka riska / E. Dzh. Khenly, Kh. Kumamoto. - M.: Mashinostroenie, 1984. - 528 p.

Received 29.01.2020. Accepted 30.01.2020.

\section{Оптимальний об'єм акумулюючих бункерів, що працюють в системі конвеєрного транспорту вугільних шахт}

у роботі розроблено математичну модель функціонування акумулюючого бункера, що працює в системі конвеєрного транспорту в режимі підтримки в ньому об'єму вантажу в заданих межах. При цьому передбачалося, що інтервали часу простоїв і роботи надбункерної та підбункерної конвеєрних ліній розподіляються за експоненціальним законами. На підставі теорії ймовірності визначено пропускну здатність системи «конвеєрбункер-конвеєр».

В результаті отримано аналітичну залежність середньої пропускної здатності системи «конвеєр-бункер-конвеєр» від об'єму бункера і середніх вантажопотоків, що надходить в бункер і розвантажується з нього. На підставі отриманої залежності визначено максимальний об'єм акумулюючого бункера, при якому пропускна здатність системи «конвеєр-бункер-конвеєр» практично не збільшується зі збільшенням об'єму бункера.

\section{Optimum volume of accumulative bunker operating in conveyer transport system of coal mines}

In the conveyor system of coal mines, storage bunkers are widely used. They allow, due to the accumulation of load in the hopper, to increase the throughput of the conveyor transport system.

Currently, there are no methods for determining the optimal volume of storage bins, in which the throughput of the conveyor transport system would be greatest.

In the work, the mathematical model of the functioning of the storage bunker working in the conveyor system in the mode of maintaining the load volume in it within the specified limits is developed. Based on the theory of probability, the throughput of the "conveyor-bunkerconveyor" system with an accumulating bunker operating in the mode of maintaining the load volume in it within specified limits has been determined.

At the same time, it was assumed that the downtime and operation intervals of the overbunker and sub-bunker conveyor lines are distributed according to exponential laws.

As a result, we obtained an analytical dependence of the average throughput of the "conveyor-bunker-conveyor" system on the volume of the bunker, the average load flows entering and unloading from the bunker, as well as on the downtime and recovery rates of the over-bunker and sub-bunker conveyor lines.

The analysis of the obtained analytical dependencies showed that the average throughput of the "conveyor-bunker-conveyor" system initially increases with increasing bunker volume and tends to a constant value with an unlimited increase in bunker volume. Moreover, if the average load flow entering the bunker is greater than the average load flow unloading from it, then the average throughput tends to the average load flow entering the bunker with an increase in the volume of the bunker. And if the average load flow entering the bunker is less than the average load flow unloaded from it, then the average throughput tends to the average load flow unloading from the bunker with an increase in the volume of the bunker. 
«Системні технології» 1 (126) 2020 «System technologies»

Based on the obtained dependence, the maximum volume of the accumulating bunker was determined, at which the throughput of the "conveyor-bunker-conveyor" system practically does not increase with increasing volume of the bunker.

Кирия Руслан Виссарионович - д.т.н., старший научный сотрудник отдела Геомеханических основ технологий открытой разработки месторождений, Институт геотехнической механики им. Н. С. Полякова Национальной академии наук Украины.

Дзюба Сергей Владимирович - к.т.н., старший научный сотрудник отдела Геодинамических систем и вибрационных технологий, Институт геотехнической механики им. Н.С. Полякова Национальной академии наук Украины.

Мостовой Борис Иванович - магистр, ведущий инженер отдела Геомеханических основ технологий открытой разработки месторождений, Институт геотехнической механики им. Н. С. Полякова Национальной академии наук Украины.

Кірія Руслан Віссаріонович - д.т.н., старший науковий співробітник відділу Геомеханічних основ технологій відкритої розробки родовищ, Iнститут геотехнічної механіки ім. М. С. Полякова Національної академії наук України.

Дзюба Сергій Володимирович - к.т.н., старший науковий співробітник відділу Геодинамічних систем і вібраційних технологій, Інститут геотехнічної механіки ім. М. С. Полякова Національної академії наук України.

Мостовий Борис Іванович - магістр, провідний інженер Інститут геотехнічної механіки ім. М. С. Полякова Національної академії наук України (ГГТМ НАН України), Дніпро, Україна, Інститут геотехнічної механіки ім. М. С. Полякова Національної академії наук України.

Kiriia Ruslan - doctor of technical sciences (d. sc), senior researcher in department of geomechanics of mineral opencast mining technology, Institute of Geotechnical Mechanics named by N. Poljakov of National Academy of Sciences of Ukraine.

Dziuba Serhii - candidate of technical sciences (ph.d), senior researcher in department of geodynamic system and vibration technologies, Institute of Geotechnical Mechanics named by N. Poljakov of National Academy of Sciences of Ukraine.

Mostovyi Borys - master of science, principal specialist in department of geomechanics of mineral opencast mining technology, Institute of Geotechnical Mechanics named by N. Poljakov of National Academy of Sciences of Ukraine. 